\title{
Board 51: An Initial Step Towards Measuring First-Generation College Stu- dents' Personal Agency: A Scale Validation
}

\author{
Ms. Dina Verdín, Purdue University-Main Campus, West Lafayette (College of Engineering)
}

Dina Verdín is a Ph.D. Candidate in Engineering Education at Purdue University. She completed her M.S. in Industrial Engineering at Purdue University and B.S. in Industrial and Systems Engineering at San José State University. Dina is a 2016 recipient of the National Science Foundation's Graduate Research Fellowship and an Honorable Mention for the Ford Foundation Fellowship Program. Her research interest focuses on changing the deficit base perspective of first-generation college students by providing asset-based approaches to understanding this population. Dina is interested in understanding how firstgeneration college students author their identities as engineers, use their agency to (re)create their multiple identities in the current culture of engineering.

\section{Dr. Allison Godwin, Purdue University-Main Campus, West Lafayette (College of Engineering)}

Allison Godwin, Ph.D. is an Assistant Professor of Engineering Education at Purdue University. Her research focuses what factors influence diverse students to choose engineering and stay in engineering through their careers and how different experiences within the practice and culture of engineering foster or hinder belongingness and identity development. Dr. Godwin graduated from Clemson University with a B.S. in Chemical Engineering and Ph.D. in Engineering and Science Education. Her research earned her a National Science Foundation CAREER Award focused on characterizing latent diversity, which includes diverse attitudes, mindsets, and approaches to learning, to understand engineering students' identity development. She has won several awards for her research including the 2016 American Society of Engineering Education Educational Research and Methods Division Best Paper Award and the 2018 Benjamin J. Dasher Best Paper Award for the IEEE Frontiers in Education Conference. She has also been recognized for the synergy of research and teaching as an invited participant of the 2016 National Academy of Engineering Frontiers of Engineering Education Symposium and the Purdue University 2018 recipient of School of Engineering Education Award for Excellence in Undergraduate Teaching and the 2018 College of Engineering Exceptional Early Career Teaching Award. 


\title{
An Initial Step Towards Measuring First-Generation College Students' Personal Agency: A Scale Validation
}

\begin{abstract}
This research paper describes the development of a scale to measure how first-generation college students use engineering as a tool for making a difference in their community and world or personal agency. Personal agency is a capability that every individual holds; it is described by Bandura as an individual's beliefs about their capabilities to exercise control over events that affect their lives through purposeful and reflective actions. Agentic actions allow students to explore, maneuver and impact their environment for the achievement of a goal or set of goals. This study identifies how cognitive processes of forethought, intention, reactivity, and reflection shape a students' agentic behavior and together influence first-generation college students' goal of making a difference in their community through their engineering degree.
\end{abstract}

Data for this study came from a large-scale survey of 3,711 first-year engineering students. First, the personal agency scale was tested for validity evidence using a split-half sampling technique. Exploratory factor analysis was conducted on one half, and confirmatory factor analysis was conducted on the other half. The exploratory and confirmatory factor analysis showed that the scale to measure personal agency is valid and reliable for the first-generation college student population.

The results of this work situate first-generation college students in engineering as active contributors to their environment. This study is an initial step in examining how first-generation college students are active producers of their own lives and not passive recipients of their life's circumstances. Personal agency can be used as a lens to understand how underrepresented students in engineering are empowered to act upon their world to (re)shape it. This theoretical framing and measurement support asset-based approaches to understanding a community of students who are often deficit theorized.

\section{Introduction: Who are First-Generation College Students?}

A first-generation college student is a broad term defined by parental level of education. Firstgeneration college students include a diverse group of students who are dedicated to their pathways into and through higher education and aspire to serve their communities through their postsecondary educational attainment. For example, a first-generation college student is Elizabeth, a committed electrical engineering (EE) student who said, "I never said, 'I'm not going to finish it or I'm going to do business instead of EE.' ... No, that was never an option for me ... I think those who do change their major I think they're weak or not committed ... commit, just do it, nothing comes easy, nobody gives you anything for free, you need to work for it" [1, p. 276]. A firstgeneration college student is also Bianca, whose aspirations to study engineering were altruistic and rooted in supporting students from her community. She said, "I wanted to do something that had to do with education, helping the students, bringing more Hispanics into science ... if I do engineering I can ... be a role model for other students ..." [2, p. 11]. Bianca's aspirations to be a role model to other underrepresented students like herself came from her personal experience, 
"Nobody told me I had the potential to do science ... but I believe that I have potential and I believe that a lot of Latino students in high school ... they [teachers and/or administrators] see them more like they are going to drop out of high school, they are not going to graduate and they see them as a lost cause, and in them, there are so much potential" [1, p. 276]. Additionally, a first-generation college student is Sam, a first-year engineering student, who grew up moving from place to place "depending on how rent was in the area ... It was very difficult to have a place to live. Sometimes rent was short." Nevertheless, she "kept good math scores" and was considered an elite math student. She said, "I was in a small class ... we were taking Algebra I as seventh graders, which was not the norm for the district I was part of. They called us the elite." Sam, in her senior year in high school, was taking a multivariable calculus course in college. Lastly, a first-generation college student is Lupe, a sixth-year mechanical engineering student whose stated, "I don't feel like an engineer" because she struggled in some of her courses; nevertheless, she held aspirations to make a difference with her degree. "One thing I do want to do with my degree is be able to give back to a community," she shared. Specifically, Lupe desired to give back to her mother, "I wanna make money to help my mom, to get her out of what we are in now ... I would see that she would sometimes have to work two jobs just to help pay the rent at the time and she owned a house ... Unfortunately, we lost the house so now we're renting." In sum, first-generation college students are shaped and reshape by their environment; they are agentic individuals, informed by the past, oriented towards the future, and adapt to the present [3].

National reports, for example from the National Center for Education Statistics, have produced findings about the current state of first-generation college students [4] or how to bridge the academic gap in postsecondary success [5]. However, these reports often frame first-generation college students as products of their circumstances rather than as agentic actors navigating a mixture of environments (i.e., environments that are imposed, selected, and constructed). In this work, we focus on understanding how first-generation engage with their environment in ways that require them to exercise their personal agency; they are not passive recipients of their life circumstances rather active producers entangled in imposed, selected, constructed environments.

These forms of environmental structures require the exercise of personal agency at different degrees and scope [6]; whereas students can actively shape their surroundings, their surroundings also shape them [3], [7], [8]. First-generation college students' daily interaction with individuals or situations (e.g., institution, classes, family, neighborhood, work, etc.) either constrain or enable them to take on particular roles and make a change in their world. Students' reaction and choices made in response to their imposed environment constitute their selected environment. For example, Elizabeth's imposed environment was the demanding curriculum in electrical engineering. While she acknowledged the curriculum was challenging and many people transfer out, she selected to remain in the rigorous environment. Choosing to stay in electrical engineering, Elizabeth constructed her environment by actively engaging with the course content, acquiring new knowledge and behaviors, leading her to degree completion [1].

First-generation college students, viewed as agentic actors, are capable of acting and changing their environment or world around them. An individuals' agency and its interaction with society have been outlined in spaces such as anthropology [9], psychology [6], [10], [11], life course studies [7], [8], [12], and the social sciences [13]. Emirbayer and Mische [3] highlighted the complexity and confusion around agency, observing that many scholars have shied away from 
opening the "black box" or have conceptualized agency as freedom, purposiveness, or choice, albeit "maintain[ing] an elusive ... vagueness" [3, p. 962]. We used Bandura's social cognitive theory [6], [11] and conceptualization of agency to define the construct and develop a measurement of agency for first-generation college students.

\section{Theoretical Framework}

Social Cognitive Theory through an Agentic Perspective

Social cognitive theory is a learning theory, derived from behaviorist and social learning frameworks [14]. Social cognitive theory contains elements of learning as both constructivist (i.e., emphasizing the learner as active in their construction and reorganization of knowledge) and socioculturalist views (i.e., emphasizing that the learner is embedded within sociocultural practices of teaching and learning) [15]. Social cognitive theory posits that peoples' performance, are neither solely driven by inner forces nor automatically shaped and controlled by external forces, rather people's performance can be understood in terms of a model of triadic reciprocity, where people are actors, producers, and receivers of their environment [16].

In Bandura's more recent work, he moves social cognitive theory to embrace an agentic perspective of human development, adaptation, and change [6], [14], [17]. Specifically, personal agency helps acknowledge that individuals are neither autonomous nor mechanical conveyers, but rather are contributors to "their own motivation and action within a system of triadic reciprocal causation" [16, p. 1175]. Personal agency is situated within a triadic reciprocal causation model, where reciprocal causality suggests an individual is a product of a complex interplay between personal factors, behavioral patterns, and the environment [11], see Figure 1.

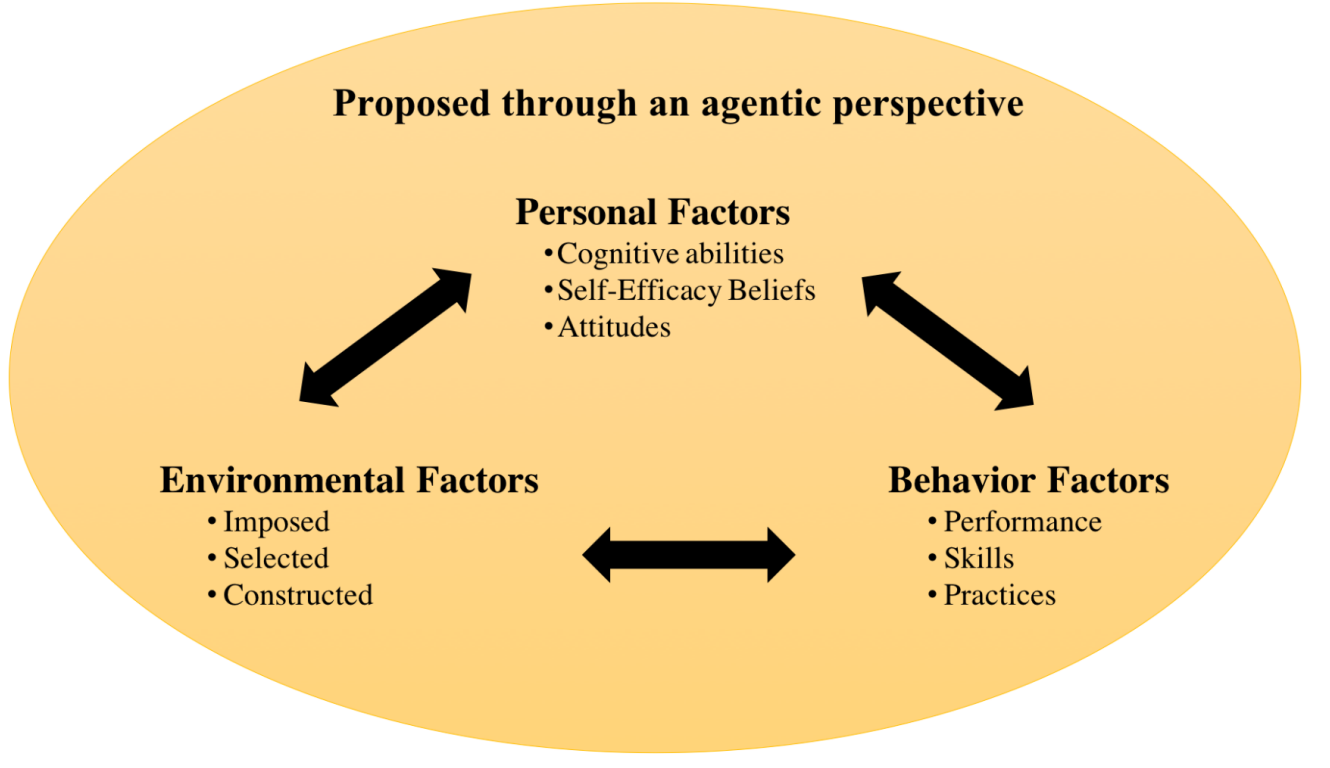

Figure 1. Bandura's Triadic Model of Reciprocal Causation [16], more recently proposed through a personal agency perspective [6], [14], [17] 
Personal factors, are forms of "cognized goals, quality of analytic thinking, and affective selfreactions," self-efficacy, expected outcomes, motivation, and dispositions to name a few [18, $\mathrm{p}$. 191]. Behavioral factors in social cognitive theory constitute knowledge acquisition through new ideas and practice. Lastly, environmental factors are not monolithic, there are three environmental structures distinguished in social cognitive theory, environments that are imposed, selected, and constructed [19]. An imposed environment may include "situations an individual must interact with on a daily basis (e.g., neighborhood, school, work, and family)” [20, p. 99].

Personal agency, in a psychological perspective, is defined as "people's beliefs about their capabilities to exercise control over events that affect their lives" [21, p. 1175]. An individual's personal agency operates within social systems; agentic actions are therefore produce and are product of social systems [22]. Personal agency is achieved through the following capabilities intentional actions, forethoughtful perspective, self-reactive a form of self-regulation, and reflectivity [11]. Forethought in personal agency goes beyond future-directed plans because future plans "cannot be a cause of current behavior," and, "through cognitive representation, visualized futures are brought into the present as current guides and motivators of behavior" [11, p. 164], [16]. For a behavior to count as agentic, the individual must take intentional actions. Intentionality is characterized as an act in which the actor knows, or believes, will have a particular outcome, and in where knowledge is utilized by the actor to achieve the outcome [6], [13]. After adopting an intentional action, the individual, drawing on their agency, should not wait for the necessary act to occur, rather through self-regulatory processes the individual links his/her plans into action (i.e., self-reactive) [11]. Lastly, the "human mind is generative, creative, proactive, and reflective, not just reactive," reflection allows for an evaluation of one's motivations and values [6, p. 4]. In social cognitive theory the capacity to self-reflect enables individuals to consider and analyze their prior experiences and thought processes [16], [23]. Consequently, an individuals' selfreflectiveness makes them active producers of knowledge and/or experiences not simply consumers of them.

In sum, personal agency can be understood as a multidirectional cyclical process, see Figure 2, wherein the achievement of a goal or outcome involves intentional actions (intentionality), forward-directed planning is done and anticipated outcomes are foreseen (forethought), appropriate courses of action are taken (self-reactiveness), and where reflection upon action is taken (self-reflectiveness) [6], [10], [11], [24]. There is bidirectional arrows to and from forethought to reflectiveness because "forethought is the product of generative and reflective ideation" [16, p. 19]. Bandura clarified that "outcomes are not the characteristics of agentive acts," rather outcomes are the consequences of agentic acts [6, p. 6]. Actions produced for a given purpose are the core feature of an individuals' agency. This graphical representation is a result of our interpretation of Bandura's literature on personal agency, reiterating the point that outcomes are consequences of agentic acts [6]. Using this conceptualization of personal agency, we seek to interpret the experiences of first-generation college students. We start by first establishing a scale to capture first-generation college students' personal agency. 


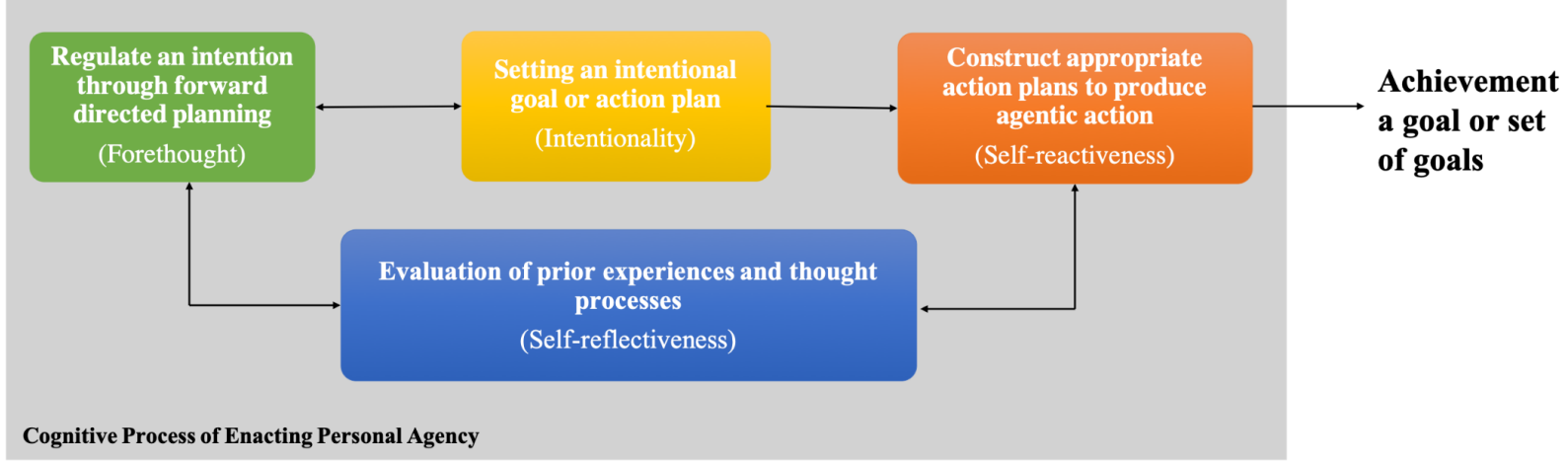

Figure 2 Process of Enacting One's Personal Agency. The conceptual flow is our own interpretation of Bandura's [6], [11] conceptualization of personal agency

\section{Purpose of this Study}

The purpose of this study was to create and test a measure of personal agency using the constructs outlined by Bandura [6], [11], i.e., forethought, intentionality, self-reactiveness, and selfreflectiveness. Developing an instrument to measure personal agency will support the broader goal of framing first-generation college students' as agentic individuals capable of (re)making their environment. To do so, we begin by validation of a scale to measure personal agency; specifically, we asked the following research questions,

RQ1. Can first-generation college students in engineering conceptually distinguish between forethought, intentionality, self-reactiveness, self-reflectiveness?

RQ2. Do the latent constructs of forethought, intentionality, self-reactiveness, selfreflectiveness create a second order latent variable (i.e., personal agency).

\section{Modifying an Existing Personal Agency Instrument}

Bandura's four personal agency constructs (i.e., forethought, intentionality, self-reactiveness, selfreflectiveness) served as a typology for the construction of the personal agency items. We conducted a thorough literature search to assess if any personal agency measurement items had been created using Bandura's four constructs. Results from the initial search found only one study that designed and tested items based on Bandura's constructs of agency.

Based on our extensive literature review of personal agency, the work of Yoon [25] was the first to create and validate a scale for personal agency using the four cognitive processes of forethought, intentionality, self-reactiveness, and self-reflectiveness as outlined by Bandura [6], [11]. The study by Yoon [25] used the personal agency constructs to examine the relationship between agency, vocational identity, and career decision self-efficacy workforce education and development for undergraduate students broadly. Our search yield no new literature on the development of personal agency measures. Yoon [25] also claimed that before his study, no scale using Bandura's personal agency constructs had been developed. 
We used survey items from Yoon's [25] original scale, making modifications and changes to several items. However, we did not adopt Yoon's [25] survey items for the latent construct selfreflectiveness; instead, we drew from the work of Kember et al. [26] who conceptualized reflection through the work of Dewey and Mezirow. Changes were made to Yoon's [25] items based on literature from Bandura [6], [11] and following the conventional wisdom for developing survey scales from Krosnick and Presser's [27]. Yoon's [25] initial survey validation process sampled a broad population, i.e., undergraduate students, graduate students, working professionals, and students enrolled in online degree programs. Additionally, Yoon's [25] recommendations for future research specifically encouraged scholars to "study a specific population" [p. 105]. Therefore, it was essential to undergo the validation process of the personal agency scale since various modifications, changes, additions were made, and it was important to understand how the scale behaved specifically with engineering students (both first-generation and continuinggeneration college students).

\section{Data Source}

Data were collected in the fall of 2017 semester from 32 four-year Accreditation Board for Engineering and Technology (ABET) institutions. Institutions were randomly selected using a stratified clustering technique by enrollment size based on data from the Integrated Postsecondary Database System [28]. Institutions with first-year engineering programs were randomly recruited from a stratified list, sampling equally from a small, medium, and large enrollment size institutions. The surveys were administered via paper-pencil format in students' introductory engineering courses. After cleaning the dataset, the overall sample of first-year engineering students was 3,711. A multiple imputation method was used to account for missing values in the dataset using an expectation maximization bootstrapping from the Amelia II package [29]. This method was appropriate as Honaker and colleagues [29] state that multiple imputation "reduces bias and increases efficiency compared to listwise deletion" [p. 3].

\section{Student Sample}

First, we coded students' college generation status. Students who responded to the question about their parent/guardian level of education for either parent/guardian as having "less than a high school diploma," "high school diploma/GED," or "some college or associate/trade degree," were coded as 1 = first-generation college students. While students who responded their parent/guardian level of education was "bachelor's degree" or "master's degree or higher," were coded as $0=$ continuing-generation college students. This dataset includes $804(22 \%)$ students who identified as first-generation college students, 2,057 (55\%) who identified as having one or more parent(s) with a bachelor's degree or higher, and $850(23 \%)$ who did not indicate parental level of education. It is difficult to determine why students do not report their parents' level of education, some possible reasons may include survey fatigue, inadequate time allocated to administering the survey in class, or the student did not know parents' level of education. The breakdown of first-generation college students' gender and race/ethnicity can be found in Table 1. Further demographic information is not presented for continuing-generation college students because this population is not the focus of the present study. 
Table 1

Demographic Information only for First-Generation College Students $(n=804)$ in First-Year

Engineering from 32 U.S. Institutions

\begin{tabular}{lc}
\hline Student Classification & \\
\hline Gender $^{++}$ & $187(24 \%)$ \\
Female & $567(72 \%)$ \\
Male & $2(0.3 \%)$ \\
Transgender & $36(4.7 \%)$ \\
Did not report or did not identify as female/male & \\
Race/Ethnicity ${ }^{++}$ & \\
Asian & $93(13 \%)$ \\
Black or African American & $67(8 \%)$ \\
Latino/a or Hispanic & $155(20 \%)$ \\
Middle Eastern or Native African & $20(3 \%)$ \\
Native American or Alaska Native & $11(1.4 \%)$ \\
Native Hawaiian or other Pacific Islander & $5(0.6 \%)$ \\
White & $408(52 \%)$ \\
Another race/ethnicity not listed above & $19(2 \%)$ \\
\hline Note. &
\end{tabular}

\section{Analysis Procedures}

A split-half sample of the large-scale dataset was used to run an exploratory factor analysis (EFA) and a confirmatory factor analysis (CFA) to test the factor structure and construct validity of personal agency. Using data from students who did not report parental level of education $(n=850)$, we ran an EFA to uncover the complex pattern structure, of the measures for personal agency, by exploring the dataset and testing predictions. Following the EFA and using data from students who identified as first-generation college students $(n=804)$, we used a CFA to reproduce the observed relationship between the latent constructs and the degree to which the model fit can be quantified using a separate population from the dataset. Additionally, CFA was "employed to evaluate the reliability of a testing instrument in a manner that overcomes limitations of traditional methods (e.g., Cronbach's alpha)" [30, p. 320].

All analysis were conducted using the R programming statistical language version 3.5.1 [31]. Confirmatory factor analysis and structural equation modeling were performed using the lavaan package [32].

\section{Results}

Exploratory Factor Analysis

Using data from students who did not report parental level of education $(n=850)$. Levels of univariate skewness and kurtosis were examined and found to be within acceptable ranges (i.e., skew $>2$; kurtosis $>7$; [33]. Mardia's test for multivariate normality failed to reject the null hypothesis of multivariate normality, skewness values $\gamma_{1, \mathrm{p}}=12.292, p<.001$ and kurtosis values $\gamma_{2, \mathrm{p}}=236.712, p<.001$, indicating the dataset is non-multivariate normal [34]. However, Bartlett's test was significant at $\left(\chi^{2}(66)=5700.17, p<0.001\right)$ and $\mathrm{KMO}=0.930$, both test indicating that the sample dataset is adequate for factor analysis. The correlation matrix was examined, and all 
variables demonstrated significant correlation. Oblique rotation was used due to the correlational nature of the variables. Ordinary least squares minimum residual was used as a factor extraction method. The scree plot and parallel analysis were examined to determine the number of common factors. After removing cross loaded items (loadings of $>0.32$ in each factor), items that were not above 0.32 factor loading threshold [35], and items with communality outside 0.40 to 0.70 threshold [36], a two-factor structure remained. Results of the two-factor structure can be found in Table 2, all items had acceptable factor loadings, communalities, and no significant cross-loading.

Table 2

Exploratory Factor Analysis using data from student who did not report parental level of education in the Large-Scale Dataset Collected in Fall $2017(n=850)$

\begin{tabular}{|c|c|c|c|c|c|}
\hline \multicolumn{2}{|c|}{ Construct } & \multirow{2}{*}{$\begin{array}{c}\text { Factor } 1 \\
0.83\end{array}$} & \multirow{2}{*}{$\frac{\text { Factor } 2}{-0.06}$} & \multirow{2}{*}{$\begin{array}{c}\text { Comm. } \\
0.69\end{array}$} & \multirow{2}{*}{$\begin{array}{c}\text { Uni. } \\
0.31\end{array}$} \\
\hline Ref. & $\begin{array}{l}\text { Q8o = I think over what I have done to consider } \\
\text { alternative ways of doing it. }\end{array}$ & & & & \\
\hline Ref. & $\begin{array}{l}\mathrm{Q} 8 \mathrm{n}=\mathrm{I} \text { think about my experiences to improve on } \\
\text { my next performance. }\end{array}$ & 0.82 & -0.01 & 0.71 & 0.29 \\
\hline Fore. & $\begin{array}{l}\mathrm{Q} 8 \mathrm{i}=\mathrm{I} \text { weigh the pros and cons before executing an } \\
\text { action. }\end{array}$ & 0.73 & 0.01 & 0.57 & 0.43 \\
\hline Fore. & $\begin{array}{l}\mathrm{Q} 8 \mathrm{~m}=\mathrm{I} \text { anticipate potential consequences when } \\
\text { making plans. }\end{array}$ & 0.71 & 0.02 & 0.54 & 0.46 \\
\hline Refl. & $\begin{array}{l}\mathrm{Q} 81=\mathrm{I} \text { reflect on my actions to see if I could have } \\
\text { made improvements. }\end{array}$ & 0.69 & 0.12 & 0.60 & 0.40 \\
\hline Fore. & $\begin{array}{l}\text { Q8d = I consider many courses of action before } \\
\text { making plans. }\end{array}$ & 0.58 & 0.18 & 0.51 & 0.49 \\
\hline Reac. & $\mathrm{Q} 8 \mathrm{f}=\mathrm{I}$ keep myself motivated to reach my goals. & -0.09 & 0.72 & 0.60 & 0.40 \\
\hline Int. & $\mathrm{Q} 8 \mathrm{e}=\mathrm{I}$ set goals to accomplish assignments. & 0.06 & 0.78 & 0.65 & 0.35 \\
\hline Int. & Q8g = My plans become actions. & 0.02 & 0.75 & 0.658 & 0.42 \\
\hline Reac. & $\begin{array}{l}\mathrm{Q} 8 \mathrm{j}=\mathrm{I} \text { actively keep myself on track to complete my } \\
\text { plans. }\end{array}$ & 0.05 & 0.71 & 0.61 & 0.39 \\
\hline Reac. & $\mathrm{Q} 8 \mathrm{~b}=\mathrm{I}$ monitor my actions to achieve my goals. & 0.10 & 0.78 & 0.64 & 0.36 \\
\hline \multicolumn{6}{|c|}{ Rotation Sum of Squared Loadings } \\
\hline & rcentage of Variance & 0.28 & 0.25 & & \\
\hline & Imulative Percentage & 0.28 & 0.54 & & \\
\hline & oportion Explained & 0.53 & 0.47 & & \\
\hline
\end{tabular}

Note. Ref. $=$ self-reflectiveness; Fore. $=$ forethought; Reac. $=$ self-reactiveness; and Int. $=$ intentionality 


\section{Confirmatory Factor Analysis}

Using a separate portion of the dataset, i.e., first-generation college students $(n=804)$, a confirmatory factor analysis was conducted to validate the findings from the EFA.

Levels of skewness and kurtosis were examined with this new dataset, all variables were within the acceptable range (i.e., skew $>2$; kurtosis $>7$ ). Multivariate normality was examined using Mardia's test. Similar to exploratory factor analysis, multivariate normality was not found in this dataset skewness values $\gamma_{1, \mathrm{p}}=19.127, p<.001$ and kurtosis values $\gamma_{2, \mathrm{p}}=251.576, p<.001$. For this analysis we used a Satorra-Bentler adjusted chi-square test for goodness of fit was used, due to a lack of multivariate normality. Results from the Satorra-Bentler chi-square goodness of fit yield $\mathrm{X}_{S B}^{2}=130.784 d f=43, p<.001$. The fit indexes were CFI of 0.967, TLI of 0.958, RMSEA of $0.051 \mathrm{CI}(0.044-0.058)$, and SRMR of 0.039 . The CFI and TLI values were above 0.90, reflecting good model fit [37]. The RMSEA value was below the recommended 0.080 value indicating good model fit with an upper confidence interval limit value also below 0.080 [30].

Table 3 provides the unstandardized and standardized factor loadings, standard error, item reliability, construct reliability, and average variance extracted for the personal agency constructs. Standardized factor loadings were above the recommended 0.45 minimum cutoff value. Item reliability for each indicator was above the recommended 0.50 minimum cutoff value [30], [35]. Construct reliability was examined using Cronbach alpha, intentionality/reactiveness $\alpha=0.857$ and reflectiveness/forethought $\alpha=0.899$ both of which are above the recommended 0.70 minimum cutoff value for each latent construct [38]. Lastly, the average amount of variance extracted (AVE) by each latent construct was above the recommended 0.50 cutoff value [39], intentionality/reactiveness AVE value 0.664 and forethought/self-reflectiveness AVE value 0.641 . Figure 3 demonstrates the first-order factor structure for the personal agency constructs of intentionality/reactiveness and self-reflectiveness/forethought. A second-order factor structure was examined to determine if the two constructs, intentionality/reactiveness and forethought/selfreflectiveness, produce a second-order latent variable called personal agency. The second-order structure can be found in Figure 4 and Table 3 provides their unstandardized and standardized factor loadings, standard error, and item reliability. 
Table 3

Confirmatory Factor Analysis for the First-Generation College Student Population in the Large-Scale Dataset Collected Fall $2017(n=804)$

\begin{tabular}{|c|c|c|c|c|c|}
\hline $\begin{array}{l}\text { Latent } \\
\text { Variables }\end{array}$ & $\begin{array}{l}\text { Unstd./Std. } \\
\text { Factor } \\
\text { Loading }\end{array}$ & $S E$ & $\begin{array}{l}\text { Item } \\
\text { Reliability }\end{array}$ & $\begin{array}{l}\text { Construct } \\
\text { Reliability }\end{array}$ & AVE \\
\hline \multicolumn{6}{|l|}{ First Order Latent Constructs } \\
\hline Intentionality/Reactiveness & & & & 0.87 & 0.62 \\
\hline $\begin{array}{l}\text { Q8f }=\text { I keep myself motivated to reach my } \\
\text { goals. }\end{array}$ & $0.50 * * * / 0.80$ & 0.03 & 0.64 & & \\
\hline $\mathrm{Q} 8 \mathrm{e}=\mathrm{I}$ set goals to accomplish assignments. & $0.45^{* * * / 0.80}$ & 0.03 & 0.64 & & \\
\hline Q8g = My plans become actions. & $0.45^{* * * / 0.78}$ & 0.03 & 0.61 & & \\
\hline $\begin{array}{l}\mathrm{Q} 8 \mathrm{j}=\mathrm{I} \text { actively keep myself on track to } \\
\text { complete my plans. }\end{array}$ & $0.50 * * * / 0.80$ & 0.03 & 0.64 & & \\
\hline $\begin{array}{l}\mathrm{Q} 8 \mathrm{~b}=\mathrm{I} \text { monitor my plans to achieve my } \\
\text { goals. }\end{array}$ & $0.43 * * * / 0.76$ & 0.03 & 0.58 & & \\
\hline Forethought/Reflectiveness & & & & 0.89 & 0.58 \\
\hline $\begin{array}{l}\mathrm{Q} 8 \mathrm{o}=\mathrm{I} \text { think over what I have done to } \\
\text { consider alternative ways of doing it. }\end{array}$ & $0.50^{* * * / 0.77}$ & 0.03 & 0.59 & & \\
\hline $\begin{array}{l}\text { Q8n }=\text { I think about my experiences to } \\
\text { improve on my next performance. }\end{array}$ & $0.54 * * * / 0.82$ & 0.04 & 0.68 & & \\
\hline $\begin{array}{l}\text { Q8i = I weigh the pros and cons before } \\
\text { executing an action. }\end{array}$ & $0.54 * * * / 0.70$ & 0.04 & 0.50 & & \\
\hline $\begin{array}{l}\mathrm{Q} 8 \mathrm{~m}=\mathrm{I} \text { anticipate potential consequences } \\
\text { when making plans. }\end{array}$ & $0.57 * * * / 0.77$ & 0.04 & 0.59 & & \\
\hline $\begin{array}{l}\mathrm{Q} 81=\mathrm{I} \text { reflect on my actions to see if I could } \\
\text { have made improvements. }\end{array}$ & $0.54 * * * / 0.80$ & 0.04 & 0.64 & & \\
\hline $\begin{array}{l}\mathrm{Q} 8 \mathrm{~d}=\mathrm{I} \text { consider many courses of action to } \\
\text { reach my plans. }\end{array}$ & $0.48^{* * * / 0.71}$ & 0.03 & 0.50 & & \\
\hline \multirow{2}{*}{\multicolumn{6}{|c|}{$\begin{array}{l}\text { Second-Order Latent Constructs } \\
\text { Personal Agency }\end{array}$}} \\
\hline & & & & & \\
\hline Intentionality/Reactiveness & $2.03 * * * / 0.90$ & 0.15 & & & \\
\hline Reflectiveness/Forethought & $1.50 * * * / 0.83$ & 0.13 & & & \\
\hline
\end{tabular}

Note. ${ }^{* * *} p<.001$; acceptable values of item reliability $\left(R^{2}\right)>.50$; construct reliability $>.70$; average variance extracted $(\mathrm{AVE})>.50$. 


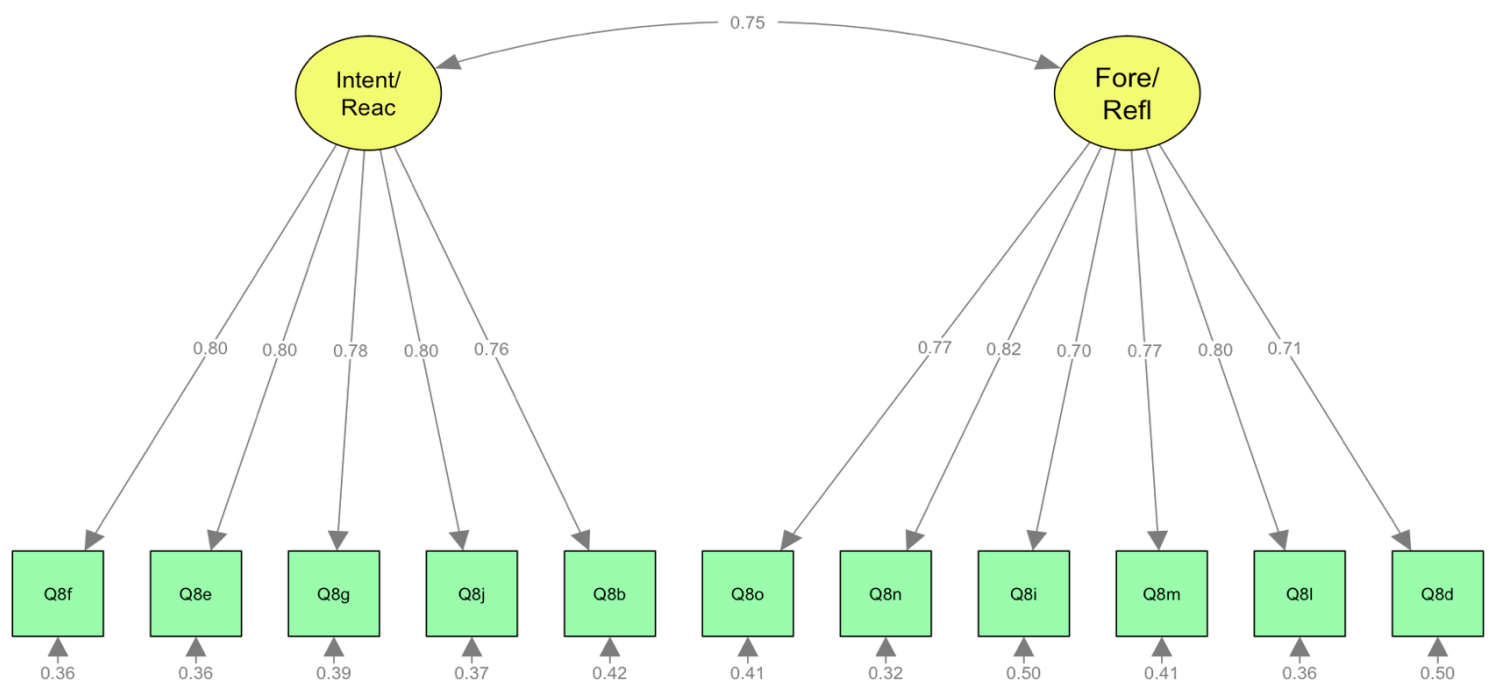

Figure 3. Results of first-order confirmatory factor analysis for personal agency

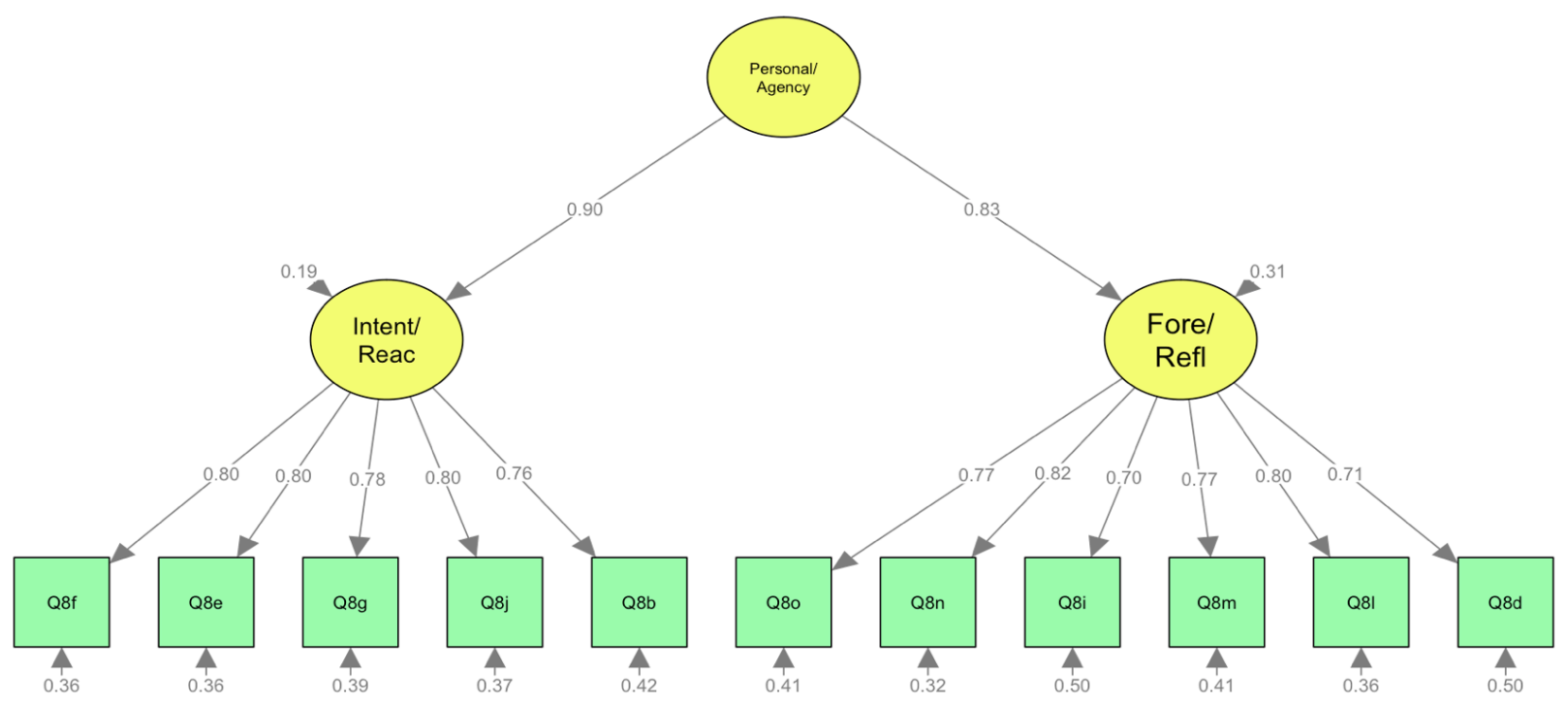

Figure 4. Results of second-order confirmatory factor analysis for personal agency 


\section{Discussion}

The results of this work situate first-generation college students in engineering as active contributors to their environment. This study is an initial step in examining how first-generation college students are active producers of their own lives and not passive recipients of their life's circumstances. To do so, we needed to understand how first-generation college students in engineering conceptualized the constructs of forethought, intentionality, self-reactiveness, selfreflectiveness. Through exploratory and confirmatory factor analysis, we found two groupings, as opposed to four, that is intentionality with self-reactiveness and forethought with selfreflectiveness. The two-factor structure demonstrated acceptable values of item and construct reliability. Based on this grouping we conclude that engineering students in our study conceptualized setting intentional plans (intentionality) and construction of appropriate courses of action to achieve these plans (self-reactiveness) similarly. The two groupings (i.e., intentionality with self-reactiveness and forethought with self-reflectiveness) was evident in the factor loadings for the two exploratory factor analysis conducted in this study. The grouping of the latent constructs was then validated using confirmatory factor analysis; all survey items demonstrated acceptable values of item and construct reliability. It is not uncommon that a scale developed using a particular sample population will function differently for another, as was the case in our study.

This study introduced social cognitive theory through a personal agency perspective, we created a scale to capture first-generation college students' personal agency. In the present conference proceeding, we do not show quantitative results using the personal agency scale rather we demonstrate how social cognitive theory grounded in a personal agency perspective can be used to frame the narratives of first-generation college students. In the opening introduction the narratives of first-generation college students offered a glimpse of how they enacted their personal agency as they navigate through various environments. That is, first-generation college students exercise their personal agency when they act against environmental factors (i.e., imposed, selected, or constructed). For example, Sam although having to move from school to school due to her parents' financial situation (i.e., imposed environment), was able to exert her agency and select an environment, in this case, her mathematics courses where she thrived despite the imposed environmental circumstances. Upon selecting mathematics as a subject of interest, Sam continued to exercise her personal agency by constructing her environment by achieving college level multivariate calculus while in high school. This brief vignette outlines how personal agency, as a conceptual framework, can be used to theorize the experiences of first-generation college students through an asset-based lens.

\section{Conclusion}

This paper is an initial effort in grounding first-generation college students' personal agency in a triadic model of reciprocal causation where students' which includes personal factors (e.g., cognitive abilities, self-efficacy beliefs, and attitudes), behavioral factors (e.g., performance and skills), and environmental factors (e.g., social-cultural settings). Personal agency can be used as a lens to understand how underrepresented students in engineering are empowered to act upon their world to (re)shape it. This theoretical framing and measurement support asset-based approaches to understanding a community of students who are often deficit theorized. 


\section{Future Work}

In a continuous effort to identify the strengths that first-generation college students enter engineering with, this work is part of a larger study that seeks to model how this population of students develop their engineering identity; identity and agency are intimately tied. The capacity students hold to exercise control over events that effect their lives and the world around them subsequently fosters identity development. First-generation college students' personal agency influence their engineering role identity because identity development is not a passive endeavor; rather identity is created, recreated, and sustained through participation in activities and reflexivity [40], [41]. Future work will capture this dynamic interplay interplay using both quantitative and qualitative data of first-generation college students.

\section{Acknowledgement}

This work is based on the first authors dissertation research. Additionally, this work was supported through funding by the National Science Foundation Graduate Research Fellowship and under the NSF CAREER Grant No. 1554057. Any opinions, findings, and conclusions or recommendations expressed in this material are those of the author(s) and do not necessarily reflect the views of the National Science Foundation.

\section{Reference}

[1] D. Verdín and A. Godwin, “Exploring Latina First-Generation College Students' Multiple Identities, Self-efficacy, and Institutional Integration to Inform Achievement in Engineering," J. Women Minor. Sci. Eng., vol. 24, no. 3, pp. 261-290, 2018.

[2] D. Verdín, A. F. Godwin, and J. L. Morazes, "Qualitative Study of First-Generation Latinas : Understanding Motivation for Choosing and Persisting in Engineering," 122nd ASEE Annu. Conf. Expo., 2015.

[3] M. Emirbayer and A. Mische, "What is agency?," Am. J. Sociol., vol. 103, no. 4, pp. 9621023, 1998.

[4] J. Redford and K. Mulvaney Hoyer, "First-Generation and Continuing-Generation College Students: A Comparison of High School and Postsecondary Experiences (NCES 2018009)," Washington, DC, 2017.

[5] U.S. Department of Education. National Center for Education Statistics, "Bridging the gap: Academic Preparation and Postsecondary Success of First-Generation Students," Washington, D.C., 2001.

[6] A. Bandura, "Social Cognitive Theory: An Agentic Perspective," Annu. Rev. Psychol., vol. 52, no. 1, pp. 1-26, 2001.

[7] A. Eteläpelto, K. Vähäsantanen, P. Hökkä, and S. Paloniemi, "What is agency? Conceptualizing professional agency at work," Educ. Res. Rev., vol. 10, pp. 45-65, 2013.

[8] S. Hitlin and G. H. Elder, "Agency: An Empirical Model of an Abstract Concept," Adv. Life Course Res., vol. 11, no. 06, pp. 33-67, 2007.

[9] D. Holland, W. Lachicotte, D. Skinner, and C. Cain, Identity and Agency in Cultural Worlds. 1998.

[10] A. Bandura, "Social cognitive theory: An agentic perspective," Asian J. Soc. Psychol., vol. 2, no. 1, pp. 21-41, 1999. 
[11] A. Bandura, "Toward a Psychology of Human Agency," Perspect. Psychol. Sci., vol. 1, no. 2, pp. 164-180, 2006.

[12] G. H. Elder, "Time, Human Agency, and Social Change: Perspectives on the Life Course," Soc. Psychol. Q., vol. 57, no. 1, pp. 4-15, 1994.

[13] A. Giddens, The constitution of society: Outline of the Theory of Structuration. Berkeley, 1984.

[14] A. Bandura, "The evolution of social cognitive theory," in Great minds in management: The process of theory development, K. G. Smith and M. A. Hitt, Eds. Oxford: Oxford University Press, 2005, pp. 9-35.

[15] J. Martin, "Self-Regulated Learning, Social Cognitive Theory, and Agency," Educ. Psychol., vol. 39, no. 2, pp. 135-145, 2004.

[16] A. Bandura, Social foundations of thought and action: A social cognitive theory. Englewood Cliffs, NJ: Prentice-Hall, Inc., 1986.

[17] A. Bandura, "Social Cognitive Theory in Cultural Context," Appl. Psychol. An Int. Rev., vol. 51, no. 2, pp. 269-290, 2002.

[18] A. Bandura, "Social Cognitive Theory of Personality," in Handbook of personality, 2nd ed., L. Pervin and O. John, Eds. New York: Guilford Publications, 1999, pp. 154-196.

[19] A. Bandura, "Social cognitive theory: An agentic Albert Bandura," Asian J. Soc. Psychol., vol. 2, pp. 21-41, 1999.

[20] K. Meaney, J. A. M. Zimmermann, Y. Lu, G. Martinez-Ramos, and J. McDonald, "Champions for health in the community: Critical service learning, transformative education, and community empowerment," in Promoting Social Justice Through the Scholarship of Teaching and Learning, D. D. Liston and R. Rahimi, Eds. Indiana University Press, 2017, p. 98-.

[21] A. Bandura, "Human agency in social cognitive theory," Am. Psychol., vol. 44, no. 9, pp. 1175-1184, 1989.

[22] A. Bandura, Self-efficacy: The exercise of control. New York: W.H. Freeman and Company, 1997.

[23] A. Stajkovic, "Social cognitive theory and self- efficacy: Implications for motivation theory and practice," no. August, 1979.

[24] A. Bandura, "Social Cognitive Theory," in University of Twent, vol. 6, R. Vasta, Ed. Greenwich: JAI Press, 1989, pp. 1-60.

[25] H. J. Yoon, "The development and validation of the assessment of human agency employing Albert Bandura's human agency theory," ProQuest Diss. Theses, vol. 3483753, no. August, p. 151, 2011.

[26] D. Kember, D. Y. P. Leung, A. Jones, A. Y. Loke, J. McKay, K. Sinclair, H. Tse, C. Webb, F. K. Yuet Wong, M. Wong, and E. Yeung, "Development of a Questionnaire to Measure the Level of Reflective Thinking," Assess. Eval. High. Educ., vol. 25, no. 4, pp. 381-395, 2000.

[27] J. a. Krosnick and S. Presser, Question and Questionnaire Design. 2010.

[28] U.S. Department of Education, \& Institute of Education Sciences National Center for Education Statistics, "IPEDS: Integrated Postsecondary Education Data System," Washington, D.C.

[29] J. Honaker, G. King, and M. Blackwell, "Amelia II: A Program for Missing Data," J. Stat. Softw., vol. 45, no. 7, pp. 1-47, 2011.

[30] T. A. Brown, Confirmatory Factor Analysis for Applied Research, 2nd ed. New York: The 
Guilford Press, 2015.

[31] R Core Team, "R: A Language and Environment for Statistical Computing." Vienna, Austria, 2018.

[32] Y. Rosseel, "lavaan : An R Package for Structural Equation," J. Stat. Softw., vol. 48, no. 2, pp. 1-36, 2012.

[33] L. R. Fabrigar, D. T. Wegener, R. C. Maccallum, and E. J. Strahan, "Evaluating the Use of Exploratory Factor Analysis in Psychological Research," Psychol. Methods, vol. 4, no. 3, pp. 272-299, 1999.

[34] S. Korkmaz, D. Goksuluk, and G. Zararsiz, "MVN: An R package for assessing multivariate normality," $R$ J., vol. 6, no. 2013, pp. 151-162, 2014.

[35] B. G. Tabachnick and L. S. Fidell, Using Multivariate Statistics. 2013.

[36] A. B. Costello and J. W. Osborne, "Best Practices in Exploratory Factor Analysis : Four Recommendations for Getting the Most From Your Analysis," Pract. Assessment, Res. Educ., vol. 10, pp. 1-9, 2005.

[37] L. Hu and P. M. Bentler, "Cutoff criteria for fit indexes in covariance structure analysis: Conventional criteria versus new alternatives," Struct. Equ. Model. A Multidiscip. J., vol. 6, no. 1, pp. 1-55, 1999.

[38] M. Tavakol and R. Dennick, "Making sense of Cronbach's alpha," Int. J. Med. Educ., vol. 2, pp. 53-55, 2011.

[39] C. Fornell and D. F. Larcker, "Evaluating Structural Equation Models with Unobservable Variables and Measurement Error," J. Mark. Res., vol. 18, no. 1, pp. 39-50, 1981.

[40] N. W. Brickhouse and J. T. Potter, "Young Women's Scientific Identity Formation in an Urban Context,” J. Res. Sci. Teach., vol. 38, no. 8, pp. 965-980, 2001.

[41] W. M. Roth, K. Tobin, R. Elmesky, C. Carambo, Y. M. McKnight, and J. Beers, "Re/Making identities in the praxis of urban schooling: A cultural historical perspective," Mind, Cult. Act., vol. 11, no. 1, pp. 48-69, 2004. 